\title{
Nietzsche entre a Pólis Grega e o Terceiro Reich Alemão
}

\author{
José Nicolao Julião*
}

\begin{abstract}
Resumo: O objetivo deste ensaio é o de analisar a interpretação que Nietzsche faz da política grega antiga e as suas implicações na crítica que ele remete à cultura moderna. Críticas essas que, muita das vezes, comprometem a sua filosofia com formas de pensamentos protofacistas. Para tal tarefa, privilegiamos, sobretudo, os estudos de juventude, nos quais, o filósofo trata da política entre os gregos, mas sem negligenciar passagens, em textos, de outras fases, quando forem relevantes para a nossa análise.
\end{abstract}

Palavras-chave: política - Estado - aristocrático

\section{Nietzsche e o Terceiro Reich Alemão}

Nietzsche, em Ecce homo, teve certo presságio de que algum dia o seu nome estaria associado a algo de terrível, assim exprimiu: "como uma crise sem igual na Terra, o mais profundo embate de consciência". (EH/EH, Por que sou um destino, 1, KSA 6.365). Sem dúvidas que o filósofo-profeta acertou quanto ao destino que lhe reservava a história, pois, o seu nome está ligado, de uma vez por todas, ao cruel e abominável movimento nazifascista que aterrorizou o mundo, poucas décadas depois de sua morte, em 1900, devido ao uso abusivo que fizeram da sua obra. Portanto, por mais que se tenha tentado desvencilhar o nome de Nietzsche do nazismo,

\footnotetext{
* Professor da Universidade Federal Rural do Rio de Janeiro (UFRRJ), Brasil.

Correio eletrônico: jnjnicolao@gmail.com.
} 
desnazificando-o, tal como, por ex., se esforçaram, primeiramente, Bataille $^{1}$, Jaspers ${ }^{2}$, Kaufmann ${ }^{3}$, o historiador americano Crane Brinton ${ }^{\mathbf{4}}$, depois, o pensamento Pós-metafísico francês dos anos 60 - Deleuze, Foucault, Derrida, Lyotard - e, mais tarde, novamente, no mundo de língua alemã, Hans Langreder ${ }^{\mathbf{5}}$ e Kurt Rudolf Fischer ${ }^{\mathbf{6}}$; mas, sobretudo, são de suma relevância para hercúlea tarefa o trabalho editorial e os ensaios de Montinari ${ }^{7}$, escritos tanto em alemão quanto em italiano; e ainda é importante ressaltar a coletânea editada por Jacob Golomb e Robert S. Wistrich ${ }^{\mathbf{}}$, na virada do século XX, 2002,

1 BATAILLE, G. Nietzsche and the Fascists. In Visions of Excess: Selectd Writings 1927-39. Manchester: Manchester University Press, 1989. Publicado pela primeira vez in Acéphale, January 1937. Na linha da Revista Acéphale, Bataille tentava resgatar Nietzsche da abjeta apropriação nazista.

2 Para o existencialista Karl Jaspers, Nietzsche foi um liberal. Cf. JASPERS, Karl. Nietzsche, Einfiihrung in das Verständnis seines Philosophierens. JASPERS, Karl. Nietzsche, Einfuihrung in das Verständnis seines Philosophierens. Unveränderte Aufl.: Berlim/Nova Iorque, 1974, pp. 254-285.

3 Walter Kaufmann considera Nietzsche um humanista e desenvolve uma interpretação alegórica espiritual de sua filosofia. Cf. KAUFMANN, W. Nietzsche: Philosopher, Psychologist, Antichrist,

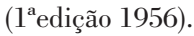

4 BRINTON, C. Nietzsche. Cambridge, Massachusetts. 1941. Importante livro que apesar de não se tratar de uma defesa explicita de Nietzsche, pois vê elementos nazistas em sua filosofia, traz, no cap. VIII, pp. 200-231 - Nietzsche and the Nazis -, um estudo sobre as relações da filosofia de Nietzsche com o Nazismo, ressaltando a gênese de tal simbiose no panorama militarista da Primeira Guerra Mundial. Nietzsche seria então para ele "meio nazista e meio antinazista".

5 LANGREDER, H. Die Auseinandersetzung mit Nietzsche im dritten Reich, Dissertation an der Universität Kiel, 1971. Importante trabalho que, utilizando o método histórico, e analisando documentos e fatos, desvencilha Nietzsche de qualquer comprometimento com o Terceiro Reich. Montinari considera esse trabalho de suma importância para a defesa de Nietzsche quanto as suas influências, de fato, sobre o Nazismo. Cf. MONTINARI, M. Interpretatione Nazista. In Su Nietzsche. Roma, 1981.

6 "Nazism as a Nietzschean "Experiment" in: Nietzsche-Studien. Vol. 6. Berlin, New York: Walter de Gruyter, 1977. Pp. 116-122. Importante artigo que mostrou que sendo o pensamento de Nietzsche um experimento pode ele de fato ser visto como precursor ou mesmo um padrinho de várias tendências, inclusive do nazismo.

7 FISCHER, K. R. Interpretatione Nazista. In Su Nietzsche. Roma, 1981. : Nietzsche zwischwen Alfred Bäumler und Georg Lukács. In Nietzsche Lesen. Berlin: Verl. Walter de Gruyter, 1982.

8 GOLOMB Jacob \& WISTRICH Rrobert. Nietzsche, Godfather of Fascism? On the uses and abuses of a philosopon Unhy. New Jersey: Princetiversity Press, 2002. Destacamos os artigos

272 | Cad. Nietzsche, Guarulhos/Porto Seguro, v.37, n.1, p. 271-296, 2016. 
que traz respeitáveis artigos sobre o não comprometimento de Nietzsche com o nazismo e formas totalitárias de poder. Entretanto, mesmo assim, desde o final dos anos 70, há uma insistente literatura que continua desfigurando o seu pensamento, ligando-o à ideologia do Nacional-Socialismo. Entre os autores que continuam comprometendo a filosofia de Nietzsche com regimes radicais de direita, temos como exemplos9: J.P. Stern, Howard Williams, Margaret Canova, Abir Taha. Segundo J.P. Stern ${ }^{10}$, ninguém incorporou melhor o modelo nietzschiano da autenticidade pessoal, que consiste em criar valores próprios para si mesmo, do que Adolf Hitler. Margaret Canova ${ }^{11}$ considera que Nietzsche, em sua preferência pela hierarquia natural em detrimento da igualdade natural, tornou-se "o pai espiritual do fascismo" e simplesmente uma fonte do pensamento protofascista. Para Howard Williams ${ }^{12}$, não é fantasioso supor que exista de fato uma afinidade entre as opiniões de Nietzsche e o fascismo. Abir Taha $^{13}$ faz ligações da filosofia de Nietzsche com a Doutrina Nazista Secreta, que ela nomeia de Nazismo Esotérico ${ }^{\mathbf{1 4}}$, especialmente no que concerne ao conceito e culto do além-do-homem.

$\mathrm{O}$ forte impulso que comprometeu o pensamento de Nietzsche com formas de políticas totalitárias tem suas origens: primeiro, nas suas ambíguas declarações sobre a democracia e o socialismo, sobre

de Müller-Lauter, Daniel Conway e Alexander Nehamas, Kurt Rudolf Fischer, o deste último é parcialmente baseado no artigo já mencionado na nota 6 .

9 Alguns destes exemplos são apresentados por Keith Ansel Pearson em seu An Introduction to Nietzsche as Political Thinker. Cambridge: Cambridge University Press, 1994, p. 32 e ss.

10 Cf. STERN, J. P. Nietzsche. Glasgow: Collins, 1978, p. 79.

11 Cf. CANOVA, M. On Being Economical with the Truth: Some Liberal Reflection. In Political Studies, 38, march, 1990, p.17.

12 Cf. WILLIAMS, H. Nietzsche and Fascism. In History of European Ideas, 11. 1989. Pp. 897-8.

13 Cf. TAHA, A. Nietzsche, Prophet of Nazis: The Cult of the Superman. 2005. Preface, vii.

14 A distinção entre Nazismo esotérico e exotérico é feita por William Bluhm para diferenciar as práticas internas e elitista da doutrina da difusão popular e ordinária da mesma. Cf. Theories of the Political System: Classic of Political Thought and Modern Political Analysis, 1978. 
os judeus e a exaltação da guerra e da crueldade como formas de se atingir uma cultura elevada, assim como na elaboração dos seus conceitos de além-do-homem e vontade de potência; segundo, na adulteração que seus textos sofreram, devido, sobretudo, à forma desorganizada e caótica como o filósofo elaborou os seus escritos, principalmente o espólio, como exemplo disso, podemos conferir o trabalho editorial organizado M-L. Haase no volume IX da KGW, York: Walter de Gruyter, 2001; ${ }^{15}$ terceiro, na forte influência que a sua obra exerceu sobre o militarismo do Segundo Reich alemão, na época da Primeira Guerra Mundial que foi transmitido ao Terceiro Reich: ${ }^{16}$ quarto, na difusão dos trabalhos de autores conservadores filiados ao partido Nacional-Socialista alemão, sobretudo Alfred

15 Haase chama atenção do leitor, entre outros, pelos persistentes erros desde a Grossoktavausgabe (GA: 1894-1926) e ainda mantido na edição crítica de Colli \& Montinari, que comprometem o pensamento de Nietzsche com o antissemitismo. Entre esses: 1. o termo "petulância de judeu" [Juden-Zudringlichkeit], apresentado no volume XIV da $G A$, p. 360, como aforismo 227, mantido na edição crítica KGW (VIII 2, 10[20]) que, de fato, se tratava de "petulância de cachorro" [HundeZudringlichkeit], corrigido agora e publicado na KGW IX 6, W II 2, p. 127, 39-41. 2., "judeus ruins" [Schlecht-Juden], que aparece no fragmento 10 [196] da KGW VIII 2, que na verdade trata-se "batalha de Sedan" [Schlacht von Sedan] - conflito travado em 1 de setembro de 1870, próximo à cidade francesa de Sedan, durante a Guerra franco-prussiana. No mesmo artigo, Haase destaca a posição crítica de Nietzsche ao antissemitismo tanto em sua correspondência quanto em anotações de cadernos (p. 44-45).Cf. HAASE, Marie-Luise. "Excursion in das Reich der Tinten-Fische und Feder-Füchse. Ein Werkestattbericht zur Edition von KGW IX". In: Nietzsche-Studien. N. 36. Berlin, New York: Walter de Gruyter, 2007, pp. 41-46.

16 Sobre a relação da filosofia de Nietzsche com o projeto militar expansionista alemão do Segundo Reich, cf. BRINTON, Crane. Nietzsche. Cambridge, Massachusetts: Harvard University Press, 1941, p. 200-206, no qual narra a culpa de guerra [Krieg-Schuld] de Nietzsche, ou seja, se a filosofia nietzschiana era estimuladora dos soldados alemães entrincheirados, pois exaltava a violência e a crueldade como forma de domínio. $\mathrm{O}$ estudo mapeia alguns livros, artigos de revista, matérias de jornais e declarações da época (entre 1914-1919) que tratavam da defesa ou acusação do envolvimento da filosofia de Nietzsche como ideologia da guerra. Portanto, foi esse primeiro impulso que teria levado os nazistas anos depois a se apropriarem da obra do filósofo, justificando o antissemitismo, a violência e a crueldade como forma de domínio e o ideal de uma super-raça expressa na figura do Übermensch.

274|Cad. Nietzsche, Guarulhos/Porto Seguro, v.37, n.1, p. 271-296, 2016. 
Bäumler, Alfred Rosenberg, Ludwig Klages, Heinrich Härtler, Richard Oehler, Oswald Spengler e Heidegger ${ }^{17}$. Entre esses, Bäumler ${ }^{18}$ e Rosenberg ${ }^{19}$ são os mais comprometedores devido ao papel que desempenhavam como ideólogos do partido. Bäumler chegou ao exagero com declarações do tipo: "E quando nós convocávamos essa juventude: 'Heil Hitler!' - ao mesmo tempo atendíamos ao chamado de Nietzsche". ${ }^{20}$ Richard Oehler, primo de Nietzsche, junto com Elizabeth Nietzsche, são responsáveis pela adulteração de textos e

17 Sobre Heidegger, é prudente observar que a sua filiação ao Nacional-Socialismo foi de curta duração e que o seu desvencilhamento se deu concomitantemente a sua aproximação com a filosofia de Nietzsche, nos anos 1936-37. Sobre a ligação de Heidegger com o nazismo cf. sua carta ao reitorado acadêmico da Universidade de Freiburg de 04/11/1945. HEIDEGGER, Martin. Carta ao Reitorado Acadêmico da Universidade de Freiburgo de 04/11/1945. In Escritos Políticos. Lisboa: Editora Instituto Piaget, p. 182. Entretanto, com a publicação dos Schwarze Hefte [Cadernos negros] reaviva o debate em torno do tema. Sobre a aproximação de Heidegger com Nietzsche e o seu afastamento do nazismo cf. FARREL KRELL, David - Heidegger et Nietzsche. In Phénoménologie et Metaphysique. Paris: PUF, 1987. Cf. também: HEINZ, M. and Th. Kisiel. "Heideggers Beziehungen zum Nietzsche-Archiv im Dritten Reich", in Annäherungen an Martin Heidegger, ed. FS Hugo Ott and v. H. Schäfer Frankfurt and New York, 1996; SLUGA, Hans D., Heidegger's Crisis: Philosophy and Politics in Nazi Germany, Harvard University Press, 1993.

18 BÄUMLER, A. Nietzsche der Philosoph und Politiker. Leipzig: Verl. Reclam, 1931. Bäumler, como professor universitário e editor de obras de Nietzsche, contribuiu para a difusão desfigurada do filósofo e teve ainda a contribuição de seu secretário Heinrich Härtler, que escreveu um manual intitulado Nietzsche und der Nationalsozialismus. Sobre o mau uso, por parte de Bäumler, dos textos de Nietzsche, cf. MONTINARI, M. Interpretatione Nazista. In Su Nietzsche. Roma, 1981.

19 Alfred Rosenberg, em Mito do Século XX, põe Nietzsche ao lado do alemão Paul de Lagarde (1827-1891) e do inglês Houton Chamberlain (1855-1927). O antissemitismo de Lagarde foi pioneiro para certos aspectos da ideologia Nacional Socialista, em particular a de Alfred Rosenberg. Ele defendia que a Alemanha deveria criar uma forma "nacional" de Cristianismo que seria expurgada dos elementos semíticos e insistia que os Judeus eram "pestes e parasitas" e que deveriam ser exterminados "tão rapidamente quanto possível”. O Racista Chamberlain, em seu livro A Gênese do Século XX, de 1899, sustentou que a raça superior ariana, descrita por Arthur de Gobineau, era ancestral de todas as classes superiores européias e da Ásia, indo mais além, afirmando que ela não havia sido extinta, subsistindo em estado puro na Alemanha (Cf. ROSENBERG, A. Der Mythus des 20. Jahrhunderts. Hoheneichen - Verlag München, 1934).

20 "Und wenn wir dieser Jugend zurufen: Heil Hitler! - so grüßen wir mit diesem Rufe zugleich Friedrich Nietzsche”. (in: Nationalsozialistische Monatshefte, Heft 49 April 1934, 5 Jg.). Publicado também em "Nietzsche und der Nazionalsozialismus". In Studien zur deutsche Geistesgeschichte. Berlin: Junker und Dünnhaupt, 1937. P. 294. 
aproximações com Hitler, que visitou o Nietzsche-Archiv, em Weimar, por duas ocasiões, em 1934. ${ }^{21}$ Hitler se reuniu pela primeira vez com Elizabeth, por intermédio de Mussolini222, já um profundo admirador do filósofo; desde os anos vinte mantinha contato com o círculo dos amigos do Nietzsche-Archiv, inclusive fornecendo ajuda financeira, além de também ser conhecido o discurso do ditador italiano no qual se refere explicitamente a Nietzsche, em 21 de maio de 1934. Além disso, como se não bastasse a apropriação e aproximações indevidas de Nietzsche com nazifascistas e com pensadores conservadores, os pensamentos de esquerda, dos anos 40 e 50 do séc. passado também contribuíram bastante para a difusão desfigurada da filosofia nietzschiana. O mais proeminente representante da esquerda que atacou contundentemente o pensamento de Nietzsche foi, sem dúvida, Lukács, que o viu como "o fundador do irracionalismo do período imperialista" e precursor do Nacional-Socialismo. ${ }^{23}$

21 Em uma dessas visitas, o Führer depositou flores no túmulo do filósofo e Elisabeth lhe presenteou com a bengala favorita do irmão, com a qual foi fotografado, olhando nos olhos do busto em mármore branco de Nietzsche. Essa foto foi feita pelo fotógrafo oficial e também biógrafo de Hitler, Heinrich Hoffmann, e foi publicada na bibliografia (que vendeu quase um milhão de meio cópias em 1938); ele caracterizou essa foto com a seguinte legenda: "o Führer diante do busto do filósofo alemão cujas ideias nutriram os dois grandes movimentos populares: o Nacional Socialismo da Alemanha e do fascismo da Itália" (Cf. SLUGA, Hans D. Heidegger's Crisis: Philosophy and Politics in Nazi Germany, Harvard University Press, 1993, p 179).

22 Gottlieb Scheuffler cita o telegrama de Elizabeth enviado a Mussolini na ocasião do seu aniversário de 50 anos em 1933, que demonstra certa admiração e intimidade da irmã do filósofo com o Duce italiano: "Para o nobre discípulo de Zaratustra que Nietzsche sonhou e inspirou despertar os valores aristocráticos, o Nietzsche-Archiv deseja os melhores e calorosos votos com profundo respeito e admiração.”. SCHEUFFLER, G. Friedrich Nietzsche im dritten Reich. Bestäntigunu und Aufgaben. Erfurt, E. Scheuffler, 1933. (Wissenschaftliche Schriftenreihe, Nr. 37), p. 7.

23 Cf. LUKÁCS, G. Die Zerstörung der Vernuft. Berlin: Aufbau-Verlag, 1953. Sobre a relação da filosofia nietzschiana com os pensamentos conservador de Bäumler e de esquerda de Lukács, cf. o ensaio de MONTINARI, M. Nietzsche zwischwen Alfred Bäumler und Georg Lukács. In Nietzsche Lesen. Berlin: Verl. Walter de Gruyter, 1982.

$276 \mid$ Cad. Nietzsche, Guarulhos/Porto Seguro, v.37, n.1, p. 271-296, 2016. 


\section{Nietzsche e a Pólis Grega}

A rotulação de nazista remetida contra Nietzsche vem daqueles que negligenciam a sua exaltação soberana e aristocrática [vornehm] ${ }^{24}$ do indivíduo tal como os gregos compreendiam e a sua forte aversão pela modernidade, sobretudo, aquela manifesta pela política com a concepção de Estado democrático herdada, segundo ele, do cristianismo ${ }^{25}$, mas que já havia sofrido traços de decadência na civilização grega clássica. A crítica nietzschiana à política, todavia, não é feita no terreno político propriamente dito, mas numa perspectiva da análise dos valores e da elevação do homem e da sua contínua superação. ${ }^{26}$ Portanto, a ideia de aristocrático desenvolvida por Nietzsche não deve ter a conotação política e militarista tal como foi empreendida pela SS nazista ${ }^{27}$, mas, antes, deve ser compreendida como uma elevação espiritual do homem, ou seja, como um radicalismo aristocrático [aristokratischer Radicalismus] ${ }^{28}$. Apesar disso ser mais evidente para os leitores do filósofo, principalmente em Para além de bem e mal e Genealogia da moral, o aristocratismo exposto nessas obras pode ser bastante esclarecido se recorrermos a alguns

$24 \mathrm{O}$ conceito de aristocrático, em Nietzsche, ao invés de lhe eximir de culpabilidade de vínculos com o nazismo, às vezes é usado para reforçar o elo; nessa direção vai Abir Taha que em seu livro, Nietzsche, Prophet of Nazis: The Cult of the Superman, op. cit., que pretende demonstrar a íntima ligação do filósofo com o abominável movimento alemão.

25 Para Nietzsche, "o movimento democrático constitui a herança do movimento cristão" (JGB/ $B M$ 202, KSA 5.125).

26 Cf. JGB/BM 257, KSA 5.205-6.

27 Cf. sobre a constituição de uma elite aristocrática, no Terceiro Reich, ZIEGLER, Hebert. Nazi Germany’s New Aristocracy - The SS Leadership, 1925-1939. 1989.

28 Em uma carta enviada a George Brandes, datada de 2 dezembro, 1887, Nietzsche lhe agradece pela expressão empregada para referir-se a sua filosofia, "aristokratischer Radicalismus". Cf. KSB 8.206. Sobre o tema do radicalismo aristocrático, Bruce Detwiler dá título ao seu livro inspirado na expressão. Cf. DETWILER, Bruce. Nietzsche and the Politics of Aristocratic Radicalism. Chicago, London: University of Chicago Press, 1990, p. 189. 
textos de juventude ${ }^{29}$ nos quais é resgatada uma ideia política do agon grego que é fundamental para compreendermos o processo funcional e orgânico da pólis grega e suas implicações na formação de cidadãos elevados. Todavia, seus detratores consideram essa ideia demasiadamente desumana, pois resgata estruturas e sentimentos de uma humanidade pagã que não eliminava do seu âmbito nem a crueldade nem a inveja, tampouco a escravidão e a violência, comportamentos repudiados pelo humanismo moderno. Nietzsche seria, portanto, um retrógrado saudosista e conservador da aristocracia grega, um precursor dos sistemas ideológicos totalitários. Desatento a certos esclarecimentos prévios, o pensamento do nosso filósofo pode realmente ser transfigurado em ideologia nazifascista, o que também pode ser extraído da rica perspectiva interpretativa que sua filosofia oferece; porém, quem for por este caminho hermenêutico, do ponto de vista político, segue o mesmo risco do cético, concernentemente ao conhecimento e o mesmo do niilista do ponto de vista metafísico e/ou moral, ou seja, está fadado ao fracasso, a autorrefutação, pois se pratica aquilo que se condena, renuncia-se àquilo que se afirma, aniquila-se, assim, a própria vida.

A ida de Nietzsche à cultura grega como modelo para a renovação e exaltação da cultura germânica, não foi uma novidade para o pensamento oitocentista, pois está em consonância com o ensinamento que começa com Winkelmann, no século anterior, que em suas Reflexões sobre a Imitação (1755-56), considerava que o único meio dos alemães se tornarem grandes e se possível inimitáveis, seria imitando os gregos antigos ${ }^{30}$, posição que influenciou fortemente toda tradição alemã do Classicismo ao Romantismo, na arte, do

29 Sobre a visão de Nietzsche do agon grego, cf. A Disputa em Homero (FV/CP 5, KSA 1.783) e O Estado Grego (CV/CP 3, KSA 1.764). Trata-se de dois dos cinco prefácios, de 1872, a livros que Nietzsche pretendia escrever, mas cuja tarefa nunca levou a cabo, mas trazem grandes esclarecimentos sobre a reflexão de Nietzsche sobre a Grécia antiga.

30 Cf. WINKELMANN, Johann J. Réflexion sur l'imitation des oevres grecques em peinture et em sculpture. Alerçon (Orne): Aubier, 1990.

278 Cad. Nietzsche, Guarulhos/Porto Seguro, v.37, n.1, p. 271-296, 2016. 
Idealismo especulativo a Schopenhauer e Nietzsche na filosofia. Esses movimentos, apesar das suas grandes diferenças, se identificavam pela exaltação da criatividade autêntica da cultura grega como modelo para renovação da cultura germânica. Nietzsche, não obstante, foi um dos primeiros, senão o primeiro, a ver na civilização grega a manifestação tanto da beleza, leveza, serenidade e altivez quanto do obscurantismo, crueldade, desespero, inveja e trapaças. Ele compreendeu o mundo grego arcaico como sendo constituído dessa dupla característica, por um lado, a harmonia e, por outro lado, também, com aquilo que é terrificante. Por isso, o filósofo de maneira alguma desconsiderava os aspectos violentos e terríveis da política grega, ele pensava que o poder e a força dessa civilização residiam justamente em graus consideráveis de inveja, crueldade e violência ${ }^{31}$. A visão nietzschiana da política saudável e violenta da pólis não pode ser compreendida sem também um esclarecimento prévio do espaço público, da arena na qual ela se constituiu.

Para Nietzsche, a política grega é uma atividade engajada daqueles que são livres de um mundo de necessidades privadas. Portanto, os homens políticos, ou seja, livres, não fazem uso da política para fins próprios, privados, mas sempre buscam a satisfação do público. Por isso, desde que os gregos se desvencilharam do domínio da necessidade e passaram a ser regidos por um logos prático, as virtudes passaram a ser as práticas exaltadas ${ }^{32}$, os homens políticos,

31 Cf. CV/CP 5. 785, KSA 1.785. Como exemplo de crueldade, Nietzsche cita a passagem do combate entre Aquiles e Heitor, na Ilíada, canto XXIII, onde o herói grego ultraja cruelmente o herói troiano.

32 A virtude (aretê) como maneira do homem grego constituir sua formação sempre foi exaltada na cultura, na paidéia grega. Assim podemos ver nos tempos de Homero, p. ex., a exaltação da coragem, manifesta em Aquiles, e a da astúcia, em Odisseu; mais tarde, com as tragédias, a exaltação da justiça e da solidariedade como as mais importantes virtudes; no período clássico, vemos em Sócrates e Platão a exaltação das virtudes cardinais, sabedoria, temperança, justiça e coragem; em Aristóteles, a exaltação da prudência. Segundo Pierre Aubenque, as origens da prudência aristotélica estariam nas tragédias gregas. Cf. AUBENQUE, Pierre. La Prudence chez Aristote. Paris: PUF, p.19 ss. Para uma leitura mais complexa dessas nuanças e mudanças de paradigmas na ética antiga grega, cf. WILLIAMS, Bernard. Shame and Necessity. California: 
livres, expressavam suas opiniões e direcionavam os caminhos da pólis em um espaço público interagido. A compreensão da simbiose entre a política e a pólis grega é então fundamental para compreendermos a posição nietzschiana de cultura e vida elevada, tal qual é descrita Segunda Extemporânea:

Isto é uma lei universal que o ser vivo pode tornar-se saudável, forte e fecundo, mas dentro de certo horizonte; se não for capaz de delimitar um círculo do seu horizonte e, por outro lado, o seu egoísmo o impede de subordinar o seu olhar ao horizonte de outrem, morrerá de preguiça ou de pressa excessiva. A serenidade, a boa consciência, a alegria na ação, a confiança no futuro, tudo isso depende, no indivíduo como na nação, da existência de uma linha de demarcação entre o que é claro e pode abarcarse com o olhar e o que é obscuro e confuso (HL/Co. Ext. II, 1, KSA 1.251).

Na última parte de Para além de bem e mal, intitulada "O que é o aristocrático? [Was ist vornehm?]", embora haja diferenças paradigmáticas consideráveis entre os dois períodos, o Nietzsche maduro, em consonância com suas reflexões juvenis, apresenta a singular relação que os gregos mantinham com a sua cidade. Os cidadãos existiam na cidade-Estado, mas não para ela,

O essencial numa boa e sã aristocracia é que esta não se sinta como uma função, seja de um rei ou de uma comunidade, mas o último significado e a mais alta justificação deles, e que recebe de boa consciência o sacrifício de inumeráveis indivíduos, que, por causa dela, devam reduzir-se a serem homens incompletos, escravos, instrumentos. $\mathrm{O}$ seu credo fundamental deve resumir-se nisso, que a sociedade não deva existir pela própria sociedade, mas simplesmente como base e como alicerce, para servir de sustentáculo, de meio de elevação para uma espécie eleita de ser para que possam atingir as suas mais altas tarefas... (JGB/BM 258, KSA 5.206). ${ }^{33}$

University of California Press, 2008.

33 Hannah Arendt, também, com bastante propriedade, chama a atenção para o espaço público no qual se constitui a cidade grega: "A rigor, a polis não é a cidade-estado em sua localização física; é a organização da comunidade que resulta do agir falar em conjunto, e seu verdadeiro

$280 \mid$ Cad. Nietzsche, Guarulhos/Porto Seguro, v.37, n.1, p. 271-296, 2016. 
No entanto, a exaltação do indivíduo soberano na cultura grega deve ser compreendida de tal forma que o espaço público que o concebe deve ser o legitimador dessa elevação, ou seja, é com o assentimento público que o indivíduo se torna elevado. Porém, para que tal instância seja inquestionável, há uma necessidade que a linguagem e o modo de pensar estejam relacionados de forma integralmente saudável com a instituição social da pólis. Para Nietzsche, a procedência da pólis e da filosofia está intimamente ligada, ou seja, o pensamento filosófico emergiu em solidariedade com as estruturas sociais e intelectuais que são próprias da cidade grega. ${ }^{34}$ Entretanto, em um determinado momento, surgiu certo predomínio do discurso racional sobre todos os outros instrumentos de poder, quer dizer, as ações e ensinamentos socráticos afrouxaram a relação orgânica antes existente, pois se introduziu o abstrato como objeto das discussões, dando mais ênfase ao especulativo teórico do que a sabedoria prática.

A relação originária entre a linguagem e a política será para Nietzsche a marca, que mais distanciará depois, o homem moderno do grego, sobretudo arcaico, pois, segundo ele, a maior característica de um grupo "forte" de homens é a sua habilidade em nomear as coisas para suas próprias vidas práticas. $\mathrm{O}$ uso da linguagem como um instrumento político é a forma como Nietzsche vê a força da sociedade grega. Na melhor época grega - para ele, o período trágico -, a pólis é a arena pública onde os cidadãos competem tanto fisica, através dos jogos, quanto e, mais importante, discursivamente, através da política. Contudo, segundo o nosso filósofo, Sócrates inaugura, de certo modo, a decadência dessa cultura, pois toma a virtude como algo que pode ser ensinado. A base da crítica de Nietzsche contra

espaço situa-se entre as pessoas que vivem juntas com os mesmos propósitos". Cf. ARENDT, Hanna. A Condição Humana. Rio de Janeiro: Ed. Forense Universitária, 2000, p. 211.

34 J. P. Vernant é defensor dessa mesma tese, só que ele minimiza bastante se comparado a Nietzsche as diferenças entre o pensamento dos Pré-socráticos e Socráticos. Cf. VERNANT, J. P. - Mito e Pensamento Entre os Gregos. São Paulo: Ed. Paz e Terra, 1990. 
Julião, J.N.

Sócrates e Eurípides é que eles fizeram da linguagem algo que pode ser ensinado e consequentemente aprendido, mas que não é acessível a quase ninguém ${ }^{35}$.

A concepção arcaica grega exemplifica, para Nietzsche, então uma relação "saudável" entre homem e política. Ele vê a cidade-Estado como um disfarce apolíneo sobre o qual os perigos da compreensão dionisíaca são transfigurados na cultura ou exteriorizados na arte da guerra. Por isso, para ele, a mais importante instituição política grega arcaica será o agon, a disputa [Weltkampf] - na qual o caos escondido no desejo de dominação e na dominação em si mesma - é vista de uma maneira saudável, tal como a continuidade e a estabilidade política. Portanto, os pré-requisitos para uma cultura elevada são assegurados. No contexto do agon, ninguém pode se tornar o melhor e ser o mais hábil para determinar por si mesmo as regras da disputa, pois deve haver um assentimento das partes envolvidas, deve haver um reconhecimento do melhor entre os pares, caso contrário, se gera a desmedida, o desequilíbrio [hybris]. Entretanto, a disputa deve ser mantida para que haja desenvolvimento e aperfeiçoamento da cultura. É à luz desse contexto que se pode compreender a passagem referente a Platão, no prefácio supracitado, intitulado A Disputa de Homero, no qual é dito que nos diálogos do filósofo, aquilo que possui um destacado sentido artístico é, nas mais das vezes, o resultado de uma rivalidade com a arte dos oradores, dos sofistas, dos dramaturgos de seu tempo, descoberta para que ele pudesse dizer por fim: "vejam, também posso fazer o que os meus melhores adversários podem; sim, posso fazê-lo melhor do que eles..." (CV/CP 5, KSA 1. 790).

Podemos compreender, da mesma forma, também, uma aprovação curiosa de Nietzsche do ostracismo: prevenir-se contra a hybris, pois isto ajuda a saúde da pólis. Segundo nosso filósofo,

35 Cf. GT/NT 11, KSA 1.75, quando Nietzsche fala da morte da tragédia. A esse respeito, cf. BEHLER, E. "Sokrates und die grieschische Tragödie. Nietzsche und die Brüder Schlegel über den Ursprung der Morderne.” In: Nietzsche Studien Band 18, Berlin/ New York: Walter de Gruyter \& Co., 1989., p. 141-157.

282 | Cad. Nietzsche, Guarulhos/Porto Seguro, v.37, n.1, p. 271-296, 2016. 
os gregos são antes de tudo homens políticos em si e realmente a história não conhece nenhum outro exemplo de um desencadeamento tão espantoso do impulso político... Esta rivalidade sangrenta de uma cidade contra outra, de uma facção contra a outra, esta cobiça mortífera das pequenas guerras... - em que sentido interpretar tal barbárie inocente do Estado grego? De onde ele retira sua desculpa diante do tribunal eterno? Orgulhoso e quieto o Estado avança, quem o conduz pelas mãos é a magnífica mulher que floresce, a sociedade grega (CV/CP 3, KSA 1.771-2).

O que é importante e torna possível a ocasional e espantosa exuberância política dos gregos é que a política e a cidade-Estado não existem por si mesmas, ou seja, a pólis não se justifica por si mesma. Conjuntamente, com a necessidade da força política, na fundação da cidade-Estado vem uma exigência para a sua manutenção e dinâmica, pois, de fato, isto é natural, não importa quão firme sejam as fundações da pólis, sem a sua manutenção nenhuma cultura pode se desenvolver. Nietzsche atribui então grande peso a esta necessidade e em decorrência disto, chama atenção para um fato ilustrativo da cultura grega: aos pais sem filhos são negados por completo os direitos cívicos. "Sem Estado, no natural bellum omnium contra omnes, a sociedade não pode de maneira alguma lançar raízes em uma escala maior e além do âmbito familiar" (CV/CP 3, KSA 1.772). Ao invés da constante luta de todos contra todos, para a sobrevivência nos tempos pré-políticos, o Estado (pelo menos, o grego) concentra erupções, talvez mais violentas, e admite: "No intervalo... sob o efeito daquela guerra concentrada e dirigida para dentro... a fim de deixar a flor luminosa do gênio brotar, assim que surjam alguns dias mais quentes" (CV/CP 3, KSA 1.772).

No entendimento de Nietzsche, o Estado, para ser saudável, deve, fundamentalmente, sempre ser uma instituição comunitária, ein Organismus. Não se trata de uma plêiade, ou seja, de uma simples coleção de indivíduos fortes reunidos no espaço político da pólis; as políticas devem acontecer, não devem ser usadas para benefício próprio, nenhum indivíduo deve se sentir fora da pólis e capaz de 
Julião, J.N.

usá-la em seu benefício próprio. O cidadão deve ter outros objetivos, ele deve se desenvolver através da cultura [Bildung] e tornar-se um tipo politicamente saudável. Para o autor do Zaratustra, uma situação de "feliz-cidade", ou seja, uma grande saúde gerando uma grande política e vice-versa foi mantida, mesmo que precariamente, em toda parte em um determinado período da história da Grécia, nomeadamente, na época trágica, por homens que eram ao mesmo tempo artistas, filósofos e homens de Estado [Staatsmänne]. Nietzsche viu, então, que os filósofos pré-socráticos e os primeiros poetas trágicos (Ésquilo e Sófocles) tinham a mesma roupagem, preenchiam aquelas exigências. Por isso, entende a Oréstia, de Ésquilo, como uma trilogia dramática sobre os problemas de mudanças na ordem social e política da consciência moral grega (Cf. CV/CP 3, KSA 1.722 ss). Em outra passagem, mencionada por ele, Tales de Mileto, reconhecendo as perigosas potencialidades desinterativas na proliferação da pólis, tenta uma unificação cultural da Grécia por meio de uma confederação política (Cf. Nachlass/FP 6 [49], KSA, 8.118). Em todo caso, esta delicada superação progressiva só pode ser mantida através de esforços de homens como Tales e Empédocles - "genuínos homens de Estado" (Nachlass/FP 6 [38], KSA, 8. 113), como Nietzsche os chama.

Sem um contínuo esforço artístico, o número de antagonismos e contradições implícitos na noção de continuidade acabaria por destruir a pólis. Como todo poder político organizado, a pólis deve manter as configurações sociais e políticas como elas são. Porém, isso é hostil ao desenvolvimento progressivo da Bildung. Mas, sem o renascimento contínuo que o homem de Estado promove, a pólis, como elemento apolíneo da cultura, constantemente tenta dominar o progenitor dionisíaco. Nietzsche demonstra essa simbiótica relação em $O$ Nascimento da tragédia. Portanto, na medida em que o Estado consegue tal domínio, ele seleciona um número de afetos através dos quais a regularidade da performance seria garantida.

284| Cad. Nietzsche, Guarulhos/Porto Seguro, v.37, n.1, p. 271-296, 2016. 
As características apolíneas do Estado constituem uma negação da necessidade de mudança. Mas, imediatamente, o Estado tenta desenvolver princípios pelos quais alguns homens nele começarão a achar agradável o que é de fato desagradável. O Estado gera então uma "falsa consciência, que alguém deveria gostar de fazer coisas desagradáveis" (MA I/HH I 474, KSA 2.308). De fato, Nietzsche escreve que a necessidade pela manutenção, na origem, cria uma estrutura de classes; desenvolvem-se então duas classes, uma de trabalho escravo e uma de trabalho livre. Essa relação de poder organizada entre as duas classes é a mais forte e típica, que depois, inconscientemente, servirá de modelo para outros tipos de relação. Entretanto, essa dicotomia se torna o foco central do Estado e gerará imediatamente problemas (Cf. MA I/HH I, 439, 450, KSA 2.286/292).

Ocorre então rapidamente uma transformação paralelamente estruturada e análoga àquela diagnosticada, posteriormente, no primeiro ensaio da Genealogia da moral, ou seja, a gênese do ressentimento. A classe inferior não deve ter motivos para adorar o Estado, pois, na relação com a classe dominante, ela é fraca e sofredora, procura uma justificação para o que lhe aconteceu e acaba por se identificar com as forças que lhe são hostis. Embora, como já mencionamos, haja mudanças paradigmáticas no processo do desenvolvimento intelectual do jovem Nietzsche, ele lançou algumas bases que depois, no pensamento maduro, se consolidarão a partir de novos padrões de avaliação. Deste modo, podemos ver no prefácio a $O$ Estado Grego a ocorrência de um exemplo:

Como se uma vontade mágica emanasse deles, (os conquistadores), as forças fracas aderem velozmente, de modo enigmático, e é miraculosa a sua transformação numa afinidade que até então não existia, na presença daquela avalanche de violência que de repente ganha volume, e sob o encanto daquele núcleo criador (CV/CP 3 , KSA 1. 770).

Essa relação é a base do ressentimento apresentada, anos 
depois, na Genealogia da moral, só que com uma linguagem própria [eigne Sprache $]^{\mathbf{3 6}}$, ou seja, sob a égide da doutrina da vontade de potência em sua simbiótica relação com as forças. A falta de organização por parte dos fracos os conduz a se unirem psiquicamente aos fortes. Para o nosso filósofo, psicologicamente, esta compensação é a fonte da genealogia da moral escrava; socialmente, isto tem uma importante consequência, pois tal desenvolvimento, no Estado, admite uma evasão da responsabilidade por parte daqueles que se identificam com este modo negativo. Na moral escrava, os homens não se comportam como indivíduos, mas como partes; através da divisão do trabalho, o Estado determina que os homens façam coisas contrárias a sua natureza. "Na moral o homem não trata a si mesmo como individuum, mas como dividuum" (MA I/HH I, 57, KSA 2.76). A necessária organização do Estado faz com que as pessoas tornemse diferentes, pela divisão de responsabilidade, do comando e da execução, através da intervenção das virtudes de obediência, do dever e do patriotismo. Assim, a organização social e o Estado em particular geram em muitos indivíduos uma conduta associada com a moral escrava. Com o tempo progressivo, isto tende a afetar toda comunidade.

A divisão do trabalho ${ }^{37}$ torna-se então o principal instrumento

36 No prefácio da Genealogia da moral, Nietzsche, ao referir-se a Humano, demasiado humano, diz: "Como tenho dito, foi à primeira vez que eu trouxe à luz aquelas hipóteses, genealógicas, as quais estes tratados são dedicados, com torpeza, que eu seria o último a querer ocultar-me, ainda sem liberdade, sem dispor de uma linguagem própria [eigne Sprache] para dizer estas coisas próprias e com múltiplas recaídas e flutuações" (EH/EH, Humano demasiado, humano 4, KSA 6.326). Talvez, possamos afirmar que no Prefácio a O Estado Grego, tal hipótese já haviam sido esboçadas.

37 O conceito de divisão do trabalho é moderno, Adam Smith, no primeiro Capítulo de Riqueza das Nações, mostra como a divisão do trabalho aumenta a produção da industria. (Cf. Investigação sobre a Natureza e a Causa da Riqueza das Nações. São Paulo: Editora Abril Cultural, Os Pensadores, 1974. P. 13 e ss.). Mesmo a divisão natural do trabalho tal como Marx descreve em O Capital ainda é num contexto das discussões da moderna ciência econômica (Cf. MARX, K. O Capital: Crítica da Economia Política. Livro 1. Vol I. 13a edição, Rio de Janeiro: Bertrand Brasil, 1989). Portanto, pode parecer anacrônico transferir tal tema para os antigos, sobretudo aos gregos para 
da organização política, porém, para Nietzsche, trata-se de uma forma de decadência, pois diminui as disposições do homem, tornando-o medíocre e de menor valor, degradando consequentemente a cultura. Sob o impacto da divisão do trabalho, o espaço político da ágora, o qual torna o agon possível, rapidamente começa a se desintegrar. O indivíduo é encorajado a ser pessoalmente irresponsável por seus atos - especialmente na produção. Como um recurso euripidiano do Deus ex machina ${ }^{\mathbf{3 8}}$, ele pode responsabilizar seus atos a uma autoridade externa. Ele pode agora agir para a atividade do Estado desde que o mundo político se torne uma máquina distinta dos indivíduos que o compõem, ele pode, evidentemente, não agir para o Estado - a existência da escolha implica na consciência do "para" como o problema. "Tudo que o homem faz a serviço do Estado, contraria a sua natureza - diz Nietzsche - é obtido através da divisão do trabalho". (Nachlass/FP 12. 11 (252), KSA, 12. 97). Através da divisão do trabalho, o Estado alimenta indivíduos incompletos, porém mais úteis e, pela primeira vez, o indivíduo pode ser considerado a partir da sua utilidade, encurtando o passo para uma consideração do próprio Estado como uma fonte de poder útil. É no meio de tais mudanças estruturais na pólis grega que ocorre um conjunto de eventos históricos, os quais aceleram o desenvolvimento da divisão do trabalho e do Estado moral escravo.

O desenvolvimento agonístico da cultura era postulado sob a base de que nenhuma pessoa ou mesmo uma pólis fosse de fato a melhor, pois senão estariam condenados a um desequilíbrio entre

quem - como Nietzsche chama atenção - nada era mais ultrajante do que o trabalho. Mesmo o trabalho artístico, como, por ex., uma escultura de Fídias, era para ser contemplada, mas o ato de fazer era desconsiderado, usando uma analogia de Plutarco, Nietzsche compara a um pai que se honra do seu filho, mas se envergonha do ato sexual que o gerou. (Cf. FV/CP 3, KSA 1. 766). 38 Esta técnica é bastante utilizada por Eurípides quando algo divino ou sobrenatural - mesmo um personagem - aparece de repente e aparam as arestas deixadas na história, p. ex., o final de: As Bacantes, Medéia, Alceste, Andrômaca e Helena. Esta técnica pode ser usada em qualquer gênero literário, porém muito criticada, hoje, devido à fraqueza do desfecho da trama. 
Julião, J.N.

as partes, gerando assim a hybris. Antes de tudo, na prática da política, com o espaço político ampliado, previne-se o povo de uma posição fora do mito político e do uso do Estado para fins privados. Nietzsche, com base em Tucídides (A Guerra do Peloponeso, 1), vê a vitória dos atenienses que venceram as Guerras Persas - narradas por Heródoto - como a fonte de uma mudança das mais importantes na orientação do mundo grego. As guerras surgiram então como um daemon ex machina, e deram fim ao conflito político grego. O perigo da existência mesma e a definição do Estado são tão grandes, e a vitória ateniense é tão completa, que Atenas se torna convencida de que a força e a predominância política são as únicas formas em que pode confiar para manter a sua supremacia e segurança. Além da vitória sobre os persas, Atenas desenvolve uma atitude de dominação através da política. Em um fragmento do verão de 1875, Nietzsche anota: “a dominação espiritual de Atenas foi um impedimento [Verhinderung] à toda reforma. Um pensamento obrigatório volta para o período em que a dominação não estava presente: isto não foi necessário; isto está por detrás da vitória sobre os persas" (Nachlass/FP 6 [27], KSA, 8.108).

Depois que isso se tornou fortemente estabelecido, passou a vigorar "a teoria abominável de que se pode servir a cultura apenas armada até os dentes e vestidos com luvas de boxe" (Nachlass/FP 6 [27], KSA, 8.108). Semelhante a Tucídides, Nietzsche percebe penosamente, exibindo seus traços por sua crença de que sem o Estado os homens se ferirão uns aos outros. Essa combinação entre acidente natural e acidente histórico levam as políticas para longe de ser uma atividade que ilumine uma cidade saudável, para ser um fim em si mesmo. Tal fato - paralelo à revolução socrática na epistemologia - é um desastre geral para toda a cultura grega. A predominância de Atenas é tão grande que nenhum inimigo externo persiste sob quem perfila as agressões que as contradições internas do Estado irão atenuar.

$288 \mid$ Cad. Nietzsche, Guarulhos/Porto Seguro, v.37, n.1, p. 271-296, 2016. 
O mais importante, na análise de Nietzsche, é que: a evolução da pólis grega seguiu certo padrão ontológico, todavia, isto não é de jeito algum inevitável neste início silvestre. Em um momento chave, a Guerra Persa deu um ímpeto diferente de mudança qualitativa à fundação estrutural do mundo grego. A importância da ocorrência histórica específica mostra que Nietzsche pensa que a ação humana concreta pode ser o que há de mais importante no curso do evento humano. Se tal realização abre a porta da possibilidade histórica, isto também retira do processo histórico alguma noção de uma lógica dialética, conduzindo inevitavelmente para uma condição social diferente.

\section{Nietzsche entre a pólis grega e o Estado moderno}

A efetivação desastrosa do Estado tem uma consequência de extremo alcance para evolução social e política tardia. Como o Estado se transformou de arena de poder em instrumento de poder, um novo tipo de homem surge para fazer uso desta ferramenta. Armado com a abstração socrática e autoconsciência, ele fica essencialmente fora do horizonte moral da comunidade. Uma vez que a maioria dos povos que permanece em comunidade se esquece, necessariamente, da origem do seu sentimento moral e põe-se ciente da inércia de sua crença não examinada, aquele que possui "autoconsciência" e poder começa a manipular o Estado para seus fins privados e próprios. Considerando o mundo político dos helenos,

não quero ocultar em quais manifestações do presente acredito reconhecer perturbações perigosas na esfera política, tão críticas para a arte quanto para a sociedade. Se deve existir homens que, por nascimento, situam-se fora dos instintos do povo, do Estado... tais homens inevitavelmente haverão de imaginar como meta última do Estado a mais imperturbável vida em conjunto de grandes comunidades políticas, nas quais seria permitido que eles perseguissem antes de tudo as próprias intenções, sem limites" (CV/ CP 3, KSA 1.772). 
Julião, J.N.

Tais homens tendem para a destruição política. É evidente que Nietzsche também via neles falhas. Em sua juventude, admirou Bismarck ${ }^{39}$, através de quem pensou um rejuvenescimento educacional da cultura alemã. Mas, rapidamente, reconheceu no político alemão um novo Alcibíades ${ }^{\mathbf{4 0}}$. Em suas apreciações sobre Bismarck e Alcibíades, o filósofo nunca indicou que ambos tivessem um papel comparável àqueles reservados aos grandes trágicos gregos e a potencialidade da cultura pan-helênica. Em seu tempo, Nietzsche via Wagner e a sua nova "cultura universal", apesar de seu lapso com o nacionalismo, como a mais importante figura da época. Assim como Tucídides, Nietzsche pensou que Péricles e Clêon cometeram muitas falhas como líderes, mas quem foi verdadeiramente responsável pela queda de Atenas foi o homem sem pátria, Alcibíades, que usou o Estado em benefício próprio.

Para o Estado ser usado, ele tem de ser avaliado, caso contrário, poderá ser perigoso se arriscar na destruição da guerra. Assim, nos tempos modernos, o aparecimento de doutrinas de ponto de vista "otimistas liberais" tende a tomar da guerra a qualidade antagônica. A consciência competitiva da guerra é mudada com o movimento de massas, particularmente suscetível de manipulação ideológica (Cf. MA I/HH I 441, KSA 2.287-8). Quando este desenvolvimento combinado com a falta de responsabilidade é engendrado pelo Estado, o perigo se torna enorme. Contrário àqueles que veem nos tempos modernos o desenvolvimento final do indivíduo autônomo, Nietzsche acha que o homem moderno não é uma personalidade, mas um mero ser isolado. Ele representa todos os átomos contra a comunidade... Ele instintivamente se eleva com outros átomos. O que ele combate, não combate como uma personalidade, mas como o representativo

39 Nietzsche tinha 17 anos quando Bismarck chegou ao poder, em 1862, do qual foi deposto somente em 1890, um ano depois do colapso mental que abalou o filósofo em Turim.

40 Segundo sucessor do governo ateniense depois da morte de Péricles. Segundo Nietzsche, com base em Tucídides, um aventureiro, egoísta responsável pela desgraça de Atenas.

$290 \mid$ Cad. Nietzsche, Guarulhos/Porto Seguro, v.37, n.1, p. 271-296, 2016. 
do átomo contra o todo. Cedo, em Schopenhauer como Educador, Nietzsche notou que "nós vivemos em um período de caos atomístico" (SE/Co. Ext. III. 4, KSA, 1. 370).

Como na moralidade escrava, a tendência através da fragmentação é criada pelo desejo de ser tornar forte. Por isso, pensa que "o indivíduo é uma peça extremamente vulnerável de vaidade e exigências onde todos devem ser iguais: onde todos devem se erguer entrepares" (Nachlass/FP 40 [26], KSA, 11.642). Este vigor possível possibilita algumas pequenas vaidades a serem satisfeitas, mas a base da cultura precisa, necessariamente, perecer. Todo mundo tornandose igual significa, para Nietzsche, todo mundo ser individualmente orientado através de seus ganhos privados, e assim na totalidade do seu ser, tornar-se matéria de igualdade para o domínio da necessidade. Essas consequências são incompatíveis com a raiz do pré-requisito agnóstico para a cultura e a política.

A consequência do desenvolvimento do estado moral escravocrata é muito clara para Nietzsche. Há uma progressiva depreciação da política. Por isso, em Para além de bem e mal, diz que

O movimento democrático não é apenas uma forma de decadência da organização política, mas uma forma de decadência, nomeada de diminuição do homem, fazendo-o medíocre e de menor valor. Esta não é a posição do homem que é contra a política, mas contrariamente, daquele que é contra as consequências humanas do que nós chamamos de política $(J G B / B M$ 203, KSA 5.126).

A visão de Nietzsche da pólis grega então serve como um contraponto ao Estado moderno que com suas pretensões e ideais de liberdade e igualdade, herdados da cultura cristã, não traz nenhuma vantagem para a vida, serve apenas a uma humanidade decadente que se satisfaz com o arrebanhamento e a planificação mediana do homem. Nietzsche então estabeleceu um critério para analisar o caráter elevado ou decadente de uma cultura, que passa a ser a vida, 
Julião, J.N.

portanto, se a cultura é elevada, a vida do cidadão com e por ela se eleva também e vice-versa. O pensamento de Nietzsche, entretanto, não tem pretensões de erguer um Estado planificador da ordem social com objetivos de domínio político, a sua pretensão é mais nobre, é espiritual e de cunho estético, não se expressaria satisfatoriamente num modelo ou sistema ideológico, pois o seu pensamento autêntico é de uma ordem mais elevada, permanente fonte de inspiração, uma eterna convocação para criação, enquanto a estética nazista é a da destruição e do extermínio, é uma caricatura grosseira da filosofia nietzschiana. O nazismo, malgrado a comparação, está para a filosofia de Nietzsche na mesma proporção que o stalinismo está para o pensamento de Marx.

\begin{abstract}
The object of this assay is to analyze the interpretation that Nietzsche makes of the politics old Greek and its implications in the critical one that it sends to the modern culture. Critical these that, much of the times, compromise its philosophy with forms of fascist thoughts. For such task, we privilege, over all, the young studies, in which, the philosopher deals with the politics between the Greeks, but without neglecting tickets, in texts, of other phases, when they will be excellent for ours analyzes.

Keyword: politics - State - aristocratic
\end{abstract}

\title{
Referências bibliográficas
}

ANDO, Gustav. "Thus spoke Adolf: Nietzsche and the perpetrators of Hitler's genocides". SAGA Revista de estudantes da Universidad Nacional de Colombia, n. 4 / II / 2001, p. 29-42.

APPEL, Fred. Nietzsche Contra Democracy. Ithaca: Cornell University Press, 1999.

ANSELL-Pearson, Keith. An Introduction to Nietzsche as Political Thinker. Cambridge: Cambridge University Press, 1994.

ARENDT, Hanna. A Condição Humana. Rio de Janeiro: Ed. Forense Universitária, 2000. $10^{\mathrm{a}}$ edição.

292 | Cad. Nietzsche, Guarulhos/Porto Seguro, v.37, n.1, p. 271-296, 2016. 
ASCHEIM, Steven. The Nietzsche Legacy in Germany 1890-1990. California: University of California Press, 1994.

AUBENQUE, Pierre. La Prudence chez Aristote. Paris: PUF, 1997.

BÄUMLER, Alfred. Nietzsche der Philosoph und Politiker. Leipzig: Verl. Reclam, 1931

. "Nietzsche und der Nazionalsozialismus". In Studien zur deutsche Geistesgeschichte. Berlin: Junker und Dünnhaupt, 1937, p. 281-294.

BATAILLE, George. Nietzsche and the Fascists. In Visions of Excess: Selectd Writings 1927-39. Manchester: Manchester University Press, 1989.

BEHLER, E. "Sokrates und die grieschische Tragödie. Nietzsche und die Brüder Schlegel über den Ursprung der Morderne." In: Nietzsche Studien Band 18, Berlin/ New York: Walter de Gruyter \& Co., 1989., p. 141-157.

BLUHM, Williams. Theories of the Political System: Classic of Political Thought and Modern Political Analysis. New Jessey: Prentice Hall, 1978.

BRINTON, Crane. Nietzsche. Cambridge, Massachusetts: Harvard University Press., 1941.

CANOVA, Margaret. On Being Economical with the Truth: Some Liberal Reflection. In Political Studies, 38, march, 1990, p. 5-20.

CASES, Cesare. Der Großherzog von Weimar. Erinnerung an Mazzino Montinari. In: Nietzsche-Studien Band 18, Berlin/ New York: Walter de Gruyter \& Co., 1989, p. 20-26

DETWILER, Bruce. Nietzsche and the Politics of Aristocratic Radicalism. Chicago, London: University of Chicago Press, 1990.

ESQUILO. Oréstia. Trad. Mário da Gama Kury. Rio de Janeiro: Jorge Zahar Editor, 1991.

FISCHER, Kurt Rudolf. "Nazism as a Nietzschean 'Experiment”". In: NietzscheStudien Band 6, Berlin/ New York: Walter de Gruyter \& Co., 1977, p. 116-122.

GOLOMB Jacob \& WISTRICH Rrobert. Nietzsche, Godfather of Fascism? On the uses and abuses of a philosophy. New Jersey: Princeton University Press, 2002. 
Julião, J.N.

HAASE, Marie-Luise. "Excursion in das Reich der Tinten-Fische und FederFüchse. Ein Werkestattbericht zur Edition von KGW IX". In: In: NietzscheStudien Band 36, Berlin/ New York: Walter de Gruyter \& Co.,, 2007, p. 41-47.

HÄRTLE, Heinrich. Nietzsche und der Nationalsozialismus. Münich: Zentraleverlag NSDAP, 1937.

HEIDEGGER, Martin. Carta ao Reitorado Acadêmico da Universidade de Freiburgo de 04/11/1945. In Escritos Políticos. Lisboa: Editora Instituto Piaget, 1997.

HEINZ, M. and Th. Kisiel. "Heideggers Beziehungen zum Nietzsche-Archiv im Dritten Reich", in Annäherungen an Martin Heidegger, ed. FS Hugo Ott and v. H. Schäfer Frankfurt and New York, 1996.

JASPERS, Karl. Nietzsche, Einführung in das Verständnis seines Philosophierens. Berlin-New York: Walter de Gruyter, 1974.

KAUFMANN, W. Nietzsche: Philosopher, Psychologist, Antichrist. New Jersey: Princeton University Press, 1974.

KRELL, David Farrel - Heidegger et Nietzsche. In Phénoménologie et Metaphysique. Paris: PUF, 1987.

LANGREDER, Hans: Die Auseinandersetzung mit Nietzsche im dritten Reich, Dissertation an der Universität Kiel, 1971.

LUKÁCS, G. Die Zerstörung der Vernuft. Berlin: Aufbau-Verlag, 1953.

MARX, K. O Capital: Crítica da Economia Política. Livro 1. Vol I. 13a edição, Rio de Janeiro: Bertrand Brasil, 1989.

MONTINARI, M. Nietzsche zwischwen Alfred Bäumler und Georg Lukács. In Nietzsche Lesen. Berlin: Verl. Walter de Gruyter, 1982.

. Interpretatione Nazista. In Su Nietzsche. Roma: Editori Riuniti, 1981.

NIETZSCHE, Friedrich. Kritische Studienausgabe. In: 14 B. - Herausgegeben von G. Colli und M. Montinari: Berlin/NY: dtv/de Gruyter, 1988.

. KGW, B. IX. (Herausgegeben von. M-L. Haase ). Berlin / New York: Walter de Gruyte. 2001.

. Frïheschriften. In: 5 B. - Herausgegeben von Hans Joachim Mette. München: Verlag C.H. Beckmünchen, 1994.

294|Cad. Nietzsche, Guarulhos/Porto Seguro, v.37, n.1, p. 271-296, 2016. 
. Sämtliche Briefe-Kritische Studienausgabe. In 8 B. dtv, Walter Gruyter: Berlin/NY: dtv/de Gruyter, 1986.

. Cinco Prefácios para Cinco Livros Escritos. Trad. de Pedro Sussekind. Rio de Janeiro: Ed. Sete Letras, 1996.

. The Will to Power. Trad. de Kaufmann, W. \& Hollingdale, R.J., New York: Randon House, 1967.

NOLTE, Ernst. Nietzsche y el Nietzscheanismo. Trad. Espanhola. Madrid: Alianza Universidad, 1995.

OTTMAnN, Henning. Philosophie und Politik bei Nietzsche. Berlin-New York: Walter de Gruyter, 1999.

ROSENBERG, A. Der Mythus des 20. Jahrhunderts. Hoheneichen - Verlag München, 1934.

SANDVOSS, E.. Hitler und Nietzsche. Gottingen: Musterschmidt Verlag, 1969.

SHIRER, William L. The Rise and Fall of the Third Reich: A history of Nazi Germany. New York, Simon and Schuster, 1960.

SLUGA, Hans D. Heidegger's Crisis: Philosophy and Politics in Nazi Germany. Harvard University Press, 1993.

SMITH, Adam. Investigação sobre a Natureza e a Causa da Riqueza das Nações. In Col. Os Pensadores. São Paulo: Editora Abril Cultural, 1978.

STERN, J.P. Nietzsche. Glasgow: Collins, 1978.

STRONG, Tracy. Friederich Nietzsche and the Politics of Transfiguration. Berkeley: University of California Press, 1975.

SCHEUFFLER, G. Friedrich Nietzsche im dritten Reich. Bestäntigunu und Aufgaben. Erfurt, E. Scheuffler, 1933. (Wissenschaftliche Schriftenreihe, Nr. 37).

TAHA, Abir. Nietzsche, Prophet of Nazis: The Cult of the Superman. Indiana: Author House, 2005.

THIELE, Leslie Paul. Friedrich Nietzsche and the Politics of the Soul. New Jersey: Princeton University Press, 1990. 
Julião, J.N.

THOMAS, R. Hinton. Nietzsche in German Politics and Society, 1880-1918. La Salle, Illinois: Open Court, 1986.

TUCÍDIDES - História da Guerra do Peloponeso. Brasília: Ed. UNB, 1999. 3 a edição.

TUGENDHAT, Ernst. Macht und Anti-Egalitarismus bei Nietzsche und Hitler - Einspruch gegen den Versuch einer Verharmlosung. In: Die Zeit, 38/2000

VERNAT, J. P. - Mito e Pensamento Entre os Gregos. São Paulo: Ed. Paz e Terra, 1990.

WARREN, Mark. Nietzsche and Political Thought. Cambridge, Mass. : MIT Press, 1988.

WILLIAMS, Bernard. Bernard Williams. Shame and Necessity. California: University of California Press, 2008.

WILLIAMS, Howard. Nietzsche and Fascism. In History of European Ideas, 11. 1989.

WINKELMANN, Johann J. Réflexion sur l'imitation des oevres grecques em peinture et em sculpture. Alerçon (Orne): Aubier, 1990.

WOTLING, Patrick. Nietzsche et le Problème de la Civilization. Paris: Presses Universitaires de France, 1995.

ZAPATA Galindo, M. Triumph des Willens zur Macht. Zur Nietzsche-Rezeption im NS-Staat. Hamburg: Argument, 1995.

ZIEGLER, Hebert, Nazi Germany's New Aristocracy - The SS Leadership, 19251939. New Jersey: Princeton University Press, 1989.

Artigo recebido para publicação em 14/08/2015. Artigo aceito para publicação em 08/10/2015.

$296 \mid$ Cad. Nietzsche, Guarulhos/Porto Seguro, v.37, n.1, p. 271-296, 2016. 